\title{
Evaluation of Mycobacterium tuberculosis cross-resistance to isoniazid, rifampicin and levofloxacin with their respective structural analogs
}

\author{
Belén Rocío Imperiale ${ }^{1}$, Ángela Beatríz Di Giulio ${ }^{2}$, Ángel Adrián Cataldi ${ }^{3}$ and Nora Susana Morcillo ${ }^{1}$
}

The emergence of drug-resistant, multidrug-resistant and extensively drug-resistant tuberculosis (TB) is of major public health concern in several countries. In this study, the pharmacodynamic relationships among the structural analogs of antibiotics belonging to the same family were taken into consideration. The aim of this study was to compare the susceptibility of Mycobacterium tuberculosis to isoniazid (INH), rifampicin and levofloxacin (LX) to their respective structural analogs, which are frequently used as second-line agents. The microplate colorimetric method was used to determine the MIC to INH, ethionamide (ETH), rifampicin, rifabutin, LX and moxifloxacin (MOX) in clinical isolates previously shown to be drug resistant. Mutations conferring drug resistance were detected by GenoType MTBDR plus and DNA sequencing. INH and ETH cross-resistance was found in $95.12 \%$ (39/41) of the INH-resistant isolates harboring a mutation in inhAP or inhA open reading frame, but rifabutin cross-resistance was observed in $90.0 \%(63 / 70)$ of the clinical isolates originally shown to be resistant to rifampicin. Isolates with high LX-resistance levels also showed high MIC to MOX. Fluoroquinolone cross-resistance was verified in isolates containing the gyrA94 and the gyrA90 mutation. In general, isolates with high INH, rifampicin and LX-resistance levels also displayed high MIC values for their structural analogs. These findings suggest the need to test in vitro the second-line drugs before their incorporation in the therapeutic schemes.

The Journal of Antibiotics (2014) 67, 749-754; doi:10.1038/ja.2014.61; published online 4 June 2014

\section{INTRODUCTION}

With the occurrence of about 9 million new tuberculosis (TB) cases each year and almost 1.5 million deaths worldwide, Mycobacterium tuberculosis remains a major infectious pathogen with great public health importance. ${ }^{1,2}$ The emergence of drug-resistant, multidrugresistant (resistant to at least rifampicin and isoniazid (INH)) and the extensively drug-resistant TB (multidrug-resistant TB with resistance also to one injectable agent, amikacin, kanamycin or capreomycin plus one fluoroquinolone (FQ)) is of major public health concern in several countries. ${ }^{2,3}$ The treatment of drug-resistant, multidrugresistant and mainly extensively drug-resistant $\mathrm{TB}$ is more difficult, creates more toxicity and takes longer than that used for fully drugsusceptible TB. The appearance of multi- and extensively drugresistant $\mathrm{TB}$ cases is often associated with treatment failure and therefore is a consequent threat to the patient's life. Moreover, the costs of treatments for multi-/extensively drug-resistant forms are very often unaffordable for low- or middle-income countries where the second-line agents are not produced. This absence of production led these countries to depend on the international organizations to acquire second-line anti-TB drugs.

Rifampicin and INH are the main first-line anti-TB drugs. In general, rifampicin resistance is considered to be an excellent marker for multidrug-resistant TB. More than $90 \%$ of rifampicin-resistant isolates are generally accepted to be associated with INH resistance. ${ }^{4,5}$ Around $95-97 \%$ of the mutations related to rifampicin resistance have been found in the region of the $r p o B$ gene, which comprises codons 507-533 (81 base pairs (bp)). ${ }^{6}$ Point mutations in codons 516, 526 and 531 of the $r p o B$ gene were the most frequently found and reported $^{7-9}$ TCG531TTG $(\mathrm{S}>\mathrm{L})$ is the predominant mutation accounting for approximately $40 \%$ of global rifampicin resistance. ${ }^{10}$ Mutations in codons 526 and 531 were related to high rifampicinresistant levels with MICs higher or equal to $32.00 \mu \mathrm{g} \mathrm{ml}^{-1} .^{11-13}$ Furthermore, mutations in rpoB516 were associated with a lower level of resistance with MICs around 2.00-32.00 $\mathrm{g} \mathrm{ml}^{-1} .14$

The existence of cross-resistance between different rifamycins, such as rifampicin and rifabutin, has been reported previously. In fact, according to previous reports, mutations in codons 516, 518, 522 and 529 are associated with low-level rifampicin resistance, but remains susceptible to rifabutin. ${ }^{15}$

On the other hand, resistance to INH is more complex in that INH seems to have several mechanisms of action. Even though some of these mechanisms remain unknown, it has been reported that the two main pathways involve the enzymes KatG and InhA. The mutation in codon 315 of the kat $G$ gene is the most commonly

\footnotetext{
${ }^{1}$ Reference Laboratory of Tuberculosis Control Program of Buenos Aires Province, Dr Cetrángolo Hospital, Florida, Buenos Aires Province, Argentina; ${ }^{2}$ Mycobacteria Laboratory, Petrona V de Cordero Hospital, San Fernando, Buenos Aires Province, Argentina and ${ }^{3}$ Biotechnology Institute, National Institute of Agricultural Technology (INTA), Los Reseros y Las Cabañas, Hurlingham, Buenos Aires Province, Argentina

Correspondence: Dr BR Imperiale, Reference Laboratory of Tuberculosis Control Program, Dr Cetrangolo Hospital, Italia 1750, Florida, Buenos Aires Province 1602, Argentina. E-mail: belen.imperiale@conicet.gov.ar or belen_imperiale@yahoo.com.ar
}

Received 7 October 2013; revised 15 April 2014; accepted 24 April 2014; published online 4 June 2014 
found within INH-resistant clinical isolates $(50-80 \%){ }^{16,17}$ This mutation decreases KatG activity by about $50 \%{ }^{18}$ and it is frequently associated with high-level INH resistance. Approximately, $8-20 \%$ of INH-resistant isolates have mutations in the promoter region of the inhA gene (inhAP), a gene that encodes an enzyme involved in mycolic acid biosynthesis. The main mutation in this gene $(\mathrm{C}-15 \mathrm{~T})$ is related to low-level INH resistance. The overexpression of InhA, caused by mutations in $\operatorname{inh} A P$, is associated with low INHresistant levels and cross-resistance to ethionamide (ETH). ETH is the structural analog of INH and is frequently used as a second-line drug in the multidrug-resistant TB treatment. ${ }^{19,20}$ ETH needs to be activated by the EthA enzyme and in this way targets InhA protein.

Point mutations located in the quinolone-resistant determining region of the gyrA gene are the main molecular mechanism responsible for FQ resistance, and mutations in codons 90 and 94 are the most frequent within FQ-resistant clinical isolates. ${ }^{21,22}$ Mutations in the gyrB gene are seldom found. ${ }^{21,23,24}$ Several authors postulated that alterations in M. tuberculosis efflux pumps may be another mechanism involved in FQ resistance. Although crossresistance among FQs has also been described, it is still recommended to confirm it phenotypically. ${ }^{25}$

The aim of this study was to compare the susceptibility of M. tuberculosis to first-line anti-TB drugs with their respective structural analogs, taking into account the pharmacodynamic relationships among antibiotics belonging to the same family. It is worth mentioning that the structural analogs are frequently used as second-line agents during TB treatments.

\section{MATERIALS AND METHODS}

A total of $144 \mathrm{INH}$-resistant $M$. tuberculosis isolates, 75 rifampicin-resistant and 9 levofloxacin-resistant (LX-resistant) isolates, according to the gold standard drug susceptibility testing methods, the indirect proportion method on Lowenstein-Jensen (LJ) and the BACTEC MGIT 960, were included to determine their resistance levels (MIC value) both to the original drugs and to the structural analogs of the first-line drugs: ETH, rifabutin and moxifloxacin MOX.

These strains were isolated from TB patients who lived in the northern region of Buenos Aires Province and were attended at the Reference Laboratory of Tuberculosis Control Program of Dr Cetrangolo Hospital between 2002 and 2012. These strains are very well characterized as their drug-resistant profile was investigated in due course by phenotypical methods such as LJ proportion method and or using the BACTEC 960 SIRE Kit System (Becton Dickinson, Buenos Aires, Argentina), and molecularly using a home-made multiplex allele-specific polymerase chain reaction system or the GenoType MTBDR ${ }^{\mathbb{R}}$ plus assay since $2010 .{ }^{26,27}$ These strains are part of the strain collection of the previously mentioned laboratory.

\section{MIC determination}

(a) The microplate colorimetric method using resazurin as redox indicator was used to determine the MIC values of INH, rifampicin, LX, ETH, rifabutin and MOX. ${ }^{28-30}$ This method uses 96 -well plates with flat bottom and lid. The liquid medium Middlebrok 7H9 (M7H9) supplemented with OADC (oleic acid, albumin, dextrose, and catalase) (Becton Dickinson) was used to fill up the plates. ${ }^{29,30}$

(b) Preparation of drugs: Stock solutions of $10000 \mu \mathrm{g} \mathrm{ml}^{-1}$ were prepared for each drug. These solutions were sterilized by filtration through $0.22 \mu \mathrm{m}$ Millipore filters, aliquoted and frozen at $-20{ }^{\circ} \mathrm{C}$ until use. Storage was no longer than 3 months. The fully drug-susceptible reference strain H37Rv ATCC 27294 was used as a drug-susceptibility testing control.

(c) Mycobacterium suspensions: Mycobacterium suspensions were prepared with turbidity comparable to $1 \mathrm{Mc}$ Farland solution $\left(10^{6}-10^{8}\right.$ colonyforming units per milliliter). A 1/25 dilution in M7H9/OADC was used to load the plates. (d) Preparation of plates: Plates containing 96 flat-bottom wells were used and prepared as follows: each well from A and $\mathrm{H}$ rows were filled with $200 \mu \mathrm{l}$ of sterile water to avoid desiccation of plates during incubation. In column 1, the well B was used as a sterile control filled only with $100 \mu \mathrm{l}$ of M7H9/ OADC, and wells C to G, growth controls, were also filled with $100 \mu \mathrm{l}$ of M7H9/OADC plus $100 \mu \mathrm{l}$ of 1/25 Mycobacterium suspension. In column 2, $100 \mu \mathrm{l}$ of M7H9/OADC were added from rows B to G. Then, $100 \mu \mathrm{l}$ of a drug suspension four times more concentrated than the initial concentration than the one that wanted to be tested was added and serial dilutions were performed. Finally, the wells were inoculated with $100 \mu \mathrm{l}$ of $1 / 25$ Mycobacterium dilution. Each following column was used to test different antibiotics.

The inoculated plates were light protected and incubated at $37^{\circ} \mathrm{C}$ for 5 days. Then, a growth control well was filled with $30.0 \mu \mathrm{l}$ of resazurin and incubated for $24 \mathrm{~h}$ (hs) more. If no color change was evidenced, a second growth control well was developed and incubated for $24 \mathrm{~h}$ more and so on. When bacterial growth was observed, the rest of the plate was filled with resazurin and reincubated $24 \mathrm{~h}$ more for the final reading.

MIC was defined as the minimal drug concentration that inhibited the microorganism growth and it was evidenced by the absence of color change of the redox indicator, resazurin.

\section{Molecular drug-resistant detection}

The detection of mutations in $r p o B, k a t G$, inh $A, g y r A$ and $g y r B$ that confer drug resistance was performed using the GenoType MTBDR plus assay and/or DNA sequencing. ${ }^{26,27}$

\section{Statistical methods}

Data were collected in an Excel 7.0 version and then exported to MedCalc 12.7 software (Mariakerke, Belgium). The statistical analysis was performed for each of the assayed drugs and the Fischer's exact or $\chi^{2}$ tests were used to evaluate the differences between the parental and their respective structural analog.

\section{RESULTS}

\section{MIC results}

Table 1 shows the results for the selected clinical isolates of redetermining the MIC values for INH, rifampicin and LX. This table shows the number of drug-resistant isolate according to the drug-resistant level found. A few number of drug-resistant clinical isolates by the LJ/BACTEC MGIT 960 showed MIC values in the range of susceptibility to the drug. These isolates were retested several times and were considered resistant to the drug as was indicated by the gold standards methods.

Table 2 shows the relationship between MIC ranges for the first-line anti-TB drugs and their structural analogs.

MIC_ETH was determined in the 144 isolates originally designated as INH resistant and $18.1 \%(26 / 144)$ of them were drug susceptible (MIC_ETH: 1.00 to $\leqslant 0.13 \mu \mathrm{g} \mathrm{ml}^{-1}$ ); 51 strains (35.4\%) showed low levels of ETH resistance (MIC_ETH: $8.00-2.00 \mu \mathrm{g} \mathrm{ml}^{-1}$ ) and 67 strains $(46.5 \%)$ showed high or intermediate levels of ETH resistance (Table 2).

MIC_rifabutin valid results were obtained in 70 out of 75 rifampicin-resistant isolates. Unfortunately, the remaining five rifampicin-resistant isolates were contaminated or did not grow during MIC_rifabutin determination. Twenty-nine (41.4\%) rifampicin-resistant isolates were distributed in the MIC_rifabutin range of: $32.00-4.00 \mathrm{~g} \mathrm{ml}^{-1}$; $34(48.6 \%)$ strains in the range of MIC_rifabutin: $2.00-0.25 \mu \mathrm{g} \mathrm{ml}^{-1}$ and 7 (10\%) rifampicin-resistant isolates showed MIC_rifabutin corresponding to values assigned to susceptible strains $\left(0.13-\leqslant 0.03 \mu \mathrm{g} \mathrm{ml}^{-1}\right)$. Therefore, cross-drug resistance between both rifamycins was verified in $90 \%$ (63/70) of the rifampicin-resistant isolates (Table 2). 
Regarding MOX, only four of the isolates that were originally highly resistant to LX also showed high MIC_MOX values $\left(8.00-2.00 \mu \mathrm{g} \mathrm{ml}^{-1}\right)$, as did one isolate that retested as susceptible

Table 1 MIC ranges to isoniazid, rifampicin and levofloxacin of phenotypically drug-resistant $\boldsymbol{M}$. tuberculosis

\begin{tabular}{|c|c|c|}
\hline Drug-resistant profile & 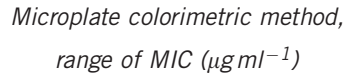 & Number of strains \\
\hline \multirow[t]{4}{*}{ INH-R (N: 144) } & $\geqslant 32.00$ & $56(38.9 \%)$ \\
\hline & $16.00-2.00$ & $64(44.4 \%)$ \\
\hline & $1.00-0.25$ & $21(14.7 \%)$ \\
\hline & $0.13-\leqslant 0.03$ & $3(2.0 \%)$ \\
\hline \multirow[t]{5}{*}{ Rifampicin-R (N: 75) } & $\geqslant 64.00$ & $46(61.3 \%)$ \\
\hline & $32.00-16.00$ & $1(1.3 \%)$ \\
\hline & $8.00-4.00$ & $14(18.7 \%)$ \\
\hline & $2.00-0.50$ & $11(14.7 \%)$ \\
\hline & $0.25-\leqslant 0.06$ & $3(4.0 \%)$ \\
\hline \multirow[t]{3}{*}{ LX-R (N: 9) } & $\geqslant 16.00-4.00$ & 5 \\
\hline & $2.00-0.50$ & 1 \\
\hline & $0.25-\leqslant 0.06$ & 3 \\
\hline
\end{tabular}

Abbreviations: INH-R: resistant to isoniazid; LX-R, resistant to levofloxacin; N, number of strains; rifampicin-R, resistant to rifampicin.

Cutoff: INH, $\geqslant 0.25 \mu \mathrm{g} \mathrm{ml}^{-1}$; rifampicin, $\geqslant 0.50 \mu \mathrm{g} \mathrm{ml}^{-1} ; \mathrm{LX}, \geqslant 0.50 \mu \mathrm{g} \mathrm{ml}^{-1}$. to LX; three other strains ranging from LX resistant to LX susceptible showed intermediate level of resistance to MOX (MIC_MOX: $\left.1.00-0.50 \mu \mathrm{g} \mathrm{ml}^{-1}\right)$. Finally, only one isolate had an MIC of $0.25 \mu \mathrm{g} \mathrm{ml}^{-1}$, which is a value usually related to LX-susceptible strains (Table 2).

\section{Molecular drug resistance}

A total of $84.7 \%(122 / 144)$ of the INH-resistant isolates had mutations conferring INH resistance; $56.3 \%$ (81/144) showed mutation in $k a t G$ and $28.5 \%(41 / 144)$ in inhA genes; mutations in the $r p o B$ gene conferring rifampicin resistance were present in $100 \%(75 / 75)$ of rifampicin-resistant isolates and only four LX-resistant isolates showed mutations in $g y r A / B$ related to resistance (Table 3 ).

\section{Relationship between drug resistance levels and mutations}

Table 4 shows the relationship between the levels of resistance for each one of the tested drugs and the mutations found conferring resistance. A total of $44.4 \%(36 / 81)$ INH-resistant isolates mutated in kat G showed high INH-resistant level (MIC_INH $\geqslant 32.00 \mu \mathrm{g} \mathrm{ml}^{-1}$ ); $50.6 \%$ (41/81) had intermediate MIC_INH values $\left(16.00-2.00 \mu \mathrm{g} \mathrm{ml}^{-1}\right)$, whereas $4.9 \%(4 / 81)$ showed low INH-resistant level (MIC_INH: $\left.1.00-0.25 \mu \mathrm{g} \mathrm{ml}^{-1}\right)$. For those isolates mutated in the inhA gene (open reading frame and promoter region), 22.0\% (9/41) had high INH-resistant level (MIC_INH $\geqslant 32.00 \mu \mathrm{g} \mathrm{ml}^{-1}$ ), 26.8\% (11/41) showed intermediate MIC values $\left(16.00-2.00 \mu \mathrm{g} \mathrm{ml}^{-1}\right), \quad 19 / 41$ (46.3\%) had low INH-resistant levels (MIC_INH: $1.00-0.25 \mu \mathrm{g} \mathrm{ml}^{-1}$ )

Table 2 Relationship between MIC ranges obtained for different first-line drugs and their structural analogs in drug-resistant $M$. tuberculosis clinical isolates

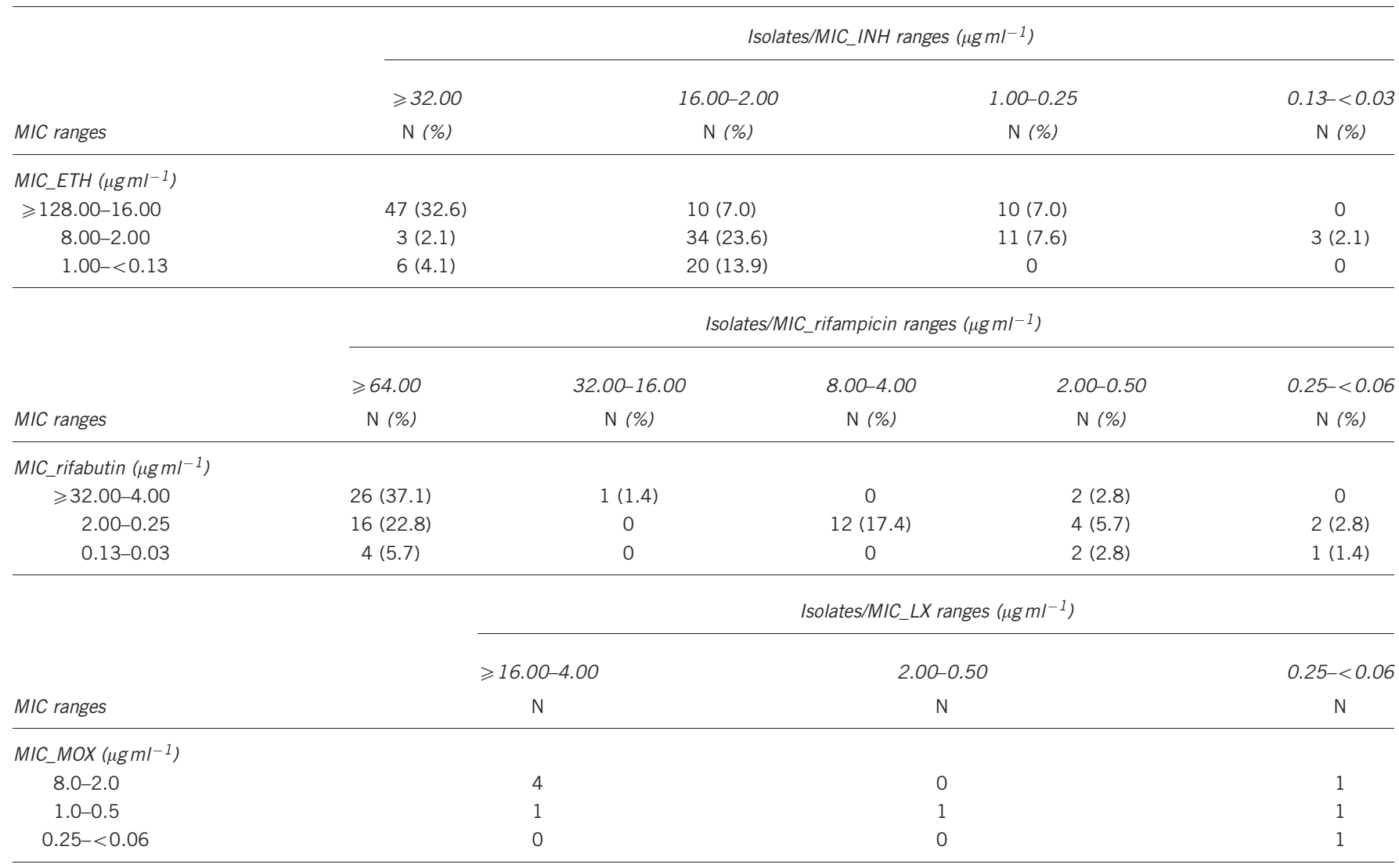

Abbreviations: MIC_rifabutin, MIC_rifampicin, MIC_INH, MIC_ETH, MIC_LX, MIC_MOX, MIC to rifabutin, rifampicin, isoniazid, ethionamide, levofloxacin and moxifloxacin; N, number. Cutoff: RIF, $\geqslant 0.50 \mu \mathrm{g} \mathrm{ml}^{-1} ; \mathrm{RBT} \geqslant 0.25 \mu \mathrm{g} \mathrm{ml}^{-1} ; \mathrm{INH}, \geqslant 0.25 \mu \mathrm{g} \mathrm{ml}^{-1} ; \mathrm{ETH}, \geqslant 2.00 \mu \mathrm{g} \mathrm{ml}^{-1} ; \mathrm{LX}^{2} \geqslant 0.50 \mu \mathrm{g} \mathrm{ml}^{-1} ; \mathrm{MOX}^{2} \geqslant 0.25 \mu \mathrm{g} \mathrm{ml}-1$. 
Table 3 Mutations found in drug-resistant isolates

\begin{tabular}{|c|c|c|c|c|c|c|c|}
\hline$D R$ & \multicolumn{7}{|c|}{ Mutations } \\
\hline & & & & & inhA codons & & \\
\hline \multirow[t]{4}{*}{ INH (N: 122/144) } & 315 & 321 & $C-15 T$ & $T-8 A$ & $G-17 T$ & 83 & 241 \\
\hline & $N(\%)$ & $N(\%)$ & $N(\%)$ & $N(\%)$ & $N(\%)$ & $N(\%)$ & $N(\%)$ \\
\hline & $80(55.5)$ & $1(0.7)$ & $36(25.0)$ & $1(2.4)$ & $1(2.4)$ & $2(4.8)$ & $1(2.4)$ \\
\hline & \multicolumn{7}{|c|}{ rpoB codons } \\
\hline \multirow[t]{4}{*}{ Rifampicin (N: 75/75) } & 513 & 516 & 522 & 526 & 531 & 572 & $513-565$ \\
\hline & N (\%) & $\mathrm{N}(\%)$ & N (\%) & $N(\%)$ & N (\%) & $N(\%)$ & N (\%) \\
\hline & $1(1.3)$ & $4(5.3)$ & $1(1.3)$ & $14(18.7)$ & $52(69.3)$ & $1(1.3)$ & $2(2.7)$ \\
\hline & & \multicolumn{6}{|c|}{ gyrA codons } \\
\hline \multirow[t]{3}{*}{$L X(N: 4 / 9)$} & & \multicolumn{2}{|c|}{90} & & & 94 & \\
\hline & & \multicolumn{2}{|c|}{$N$} & & & N & \\
\hline & & \multicolumn{2}{|c|}{1} & & & 3 & \\
\hline
\end{tabular}

Abbreviations: DR, drug resistant; INH, isoniazid; LX, levofloxacin; N, number.

and only $2(4.9 \%)$ had MIC_INH: $0.13-0.03 \mu \mathrm{g} \mathrm{ml}^{-1}$. Using the Fisher's exact test, it was observed that a significant difference between mutations in kat $G$ and $i n h A$ when the isolate had high ( $P$ : 0.035296) and intermediate INH-resistant levels ( $P$ : 0.025755). However, the difference between inhA and kat $G$ was highly significant $(P<0.000001)$ when the isolate showed low INH-resistant levels.

Therefore, these results show that, as was previously reported by other authors, the presence of the $k a t G$ mutation is linked to stronger resistance to INH than is the inhA mutation.

Determination of the MIC for ETH in the phenotypically INHresistant isolates showed 26 isolates susceptible to ETH (MIC_ETH: $1.00-\leqslant 0.13 \mu \mathrm{g} \mathrm{ml}^{-1}$ ), the majority of which bore the kat $G$ mutation that conferred INH resistance. An additional 60 isolates resistant to both INH and ETH with a kat $G$ mutation also displayed ETH resistance, whereas 40 out of 41 (97.6\%) INH-resistant isolates with the inhAP mutation showed ETH resistance $(60.0 \%$, 24/40, with MIC_ETH: $128.00-16.00 \mu \mathrm{g} \mathrm{ml}^{-1}$; 32.5\%, 13/40, with MIC_ETH: $8.00-2.00 \mu \mathrm{g} \mathrm{ml}^{-1}$ ). The remaining INH-resistant isolates with MIC_INH: $0.25 \mu \mathrm{g} \mathrm{ml}^{-1}$ had MIC_ETH: $0.13 \mu \mathrm{g} \mathrm{ml}^{-1}$. One of the INH-resistant isolates with an inhA83 mutation had MIC_INH of 1.00 and MIC_ETH of $2.00 \mu \mathrm{g} \mathrm{ml}^{-1}$, and the other isolates with the same inhA mutation showed MIC_INH: $8.00 \mu \mathrm{g} \mathrm{ml}^{-1}$ and also an MIC_ETH of $2.00 \mu \mathrm{g} \mathrm{ml}^{-1}$. The isolate with the inhA241 mutation had MIC_INH and MIC_ETH of $2.00 \mu \mathrm{g} \mathrm{ml}^{-1}$, the highest MIC values to consider an isolate still susceptible to ETH.

Regarding resistance to rifampicin, 36/49 (73.5\%) of rifampicinresistant isolates with the rpoB531 mutation had a high rifampicinresistant level (MIC_rifampicin: $\geqslant 64.00 \mu \mathrm{g} \mathrm{ml}^{-1}$ ); $16.3 \%(8 / 49)$ and $10.2 \%(5 / 49)$ had intermediate $\left(8.00-4.00 \mu \mathrm{g} \mathrm{ml}^{-1}\right)$ and low MIC values $\left(\leqslant 2.00 \mu \mathrm{g} \mathrm{ml}^{-1}\right)$, respectively. For those rifampicin-resistant isolates with rpoB526 mutation, 8 out of 14 had high resistance level (MIC_rifampicin: $\geqslant 64.00 \mu \mathrm{g} \mathrm{ml}^{-1}$ ); 3 out of 14 had intermediate $\left(8.00-4.00 \mu \mathrm{g} \mathrm{ml}^{-1}\right.$ ) and 3 showed low MIC values (MIC_rifampicin: $\leqslant 2.00 \mu \mathrm{g} \mathrm{ml}^{-1}$ ). Three isolates containing the rpoB516 mutation had MIC_rifampicin of $\geqslant 64.00 \mu \mathrm{g} \mathrm{ml}^{-1}$ and the remaining isolate displayed MIC_rifampicin of $16.00 \mu \mathrm{g} \mathrm{ml}^{-1}$.
Seven rifampicin-resistant strains tested for rifabutin were susceptible to this drug (MIC_rifabutin: $0.13-\leqslant 0.03 \mu \mathrm{g} \mathrm{ml}^{-1}$ ); two of these isolates had the rpoB526 mutation with low rifampicin-resistant level (MIC_rifampicin: 0.13 and $1.00 \mu \mathrm{g} \mathrm{ml}^{-1}$ ); four isolates, two with the rpoB516 mutation and two with the rpoB531, had MIC_rifampicin of $16.00-64.00 \mu \mathrm{g} \mathrm{ml}^{-1}$ and the remaining one showed low MIC_ rifampicin of $0.13 \mu \mathrm{g} \mathrm{ml}^{-1}$, but no rpoB mutation conferring rifampicin resistance was found. Cross-drug resistance between both rifamycins was found for the rest of the isolates. Those isolates mutated in other codons of the rifampicin resistance determining region ( 1 in rpoB513, 1 in rpoB522 and 2 in rpoB513-565) showed MIC_rifampicin of $8.00 \mu \mathrm{g} \mathrm{ml}^{-1}$ and MIC_rifabutin of $0.50 \mu \mathrm{g} \mathrm{ml}^{-1}$, whereas the isolate with the rpoB572 mutation displayed MIC_rifampicin of $2.00 \mu \mathrm{g} \mathrm{ml}^{-1}$ and MIC_rifabutin of $0.25 \mu \mathrm{g} \mathrm{ml}^{-1}$.

Regarding the FQs, five out of nine LX-resistant isolates showed high resistance levels (MIC_LX: $16.00-4.00 \mu \mathrm{g} \mathrm{ml}^{-1}$ ), whereas three of them had the gyrA94 mutation with high MIC_MOX values $\left(8.00-2.00 \mu \mathrm{g} \mathrm{ml}^{-1}\right)$. The two remaining isolates showed WT sequence in gyrA and $g y r B$, with lower resistance level to MOX (MIC_MOX: 2.00 and $0.50 \mu \mathrm{g} \mathrm{ml}^{-1}$ ). The isolate with the $g y r A 90$ mutation had intermediate resistance level to FQ with MIC_LX of $0.50 \mu \mathrm{g} \mathrm{ml}^{-1}$ and MIC_MOX of $1.00 \mu \mathrm{g} \mathrm{ml}^{-1}$. Three LX-resistant isolates, determined by the LJ proportion method and without detected mutation in gyrA nor gyrB, showed low MIC_LX values $\left(0.25 \mu \mathrm{g} \mathrm{ml}^{-1}\right)$, and only one of them also showed low MOX-resistant levels $\left(0.25 \mu \mathrm{g} \mathrm{ml}^{-1}\right)$. In addition, the other two isolates showed higher MOX-resistant levels (MIC_MOX: 8.00 and $0.50 \mu \mathrm{g} \mathrm{ml}^{-1}$ ).

\section{DISCUSSION}

\section{INH-ETH}

The inhAP mutation has been previously reported to confer crossresistance between INH and ETH. ${ }^{10}$ This finding is supported by the results herein reported, as most of the INH-resistant isolates with the mutation in the promoter region of inhA showed cross-resistance with ETH; therefore, this mechanism could be responsible for the 
Table 4 Relationship between drug-resistant levels and mutations in M. tuberculosis isolates

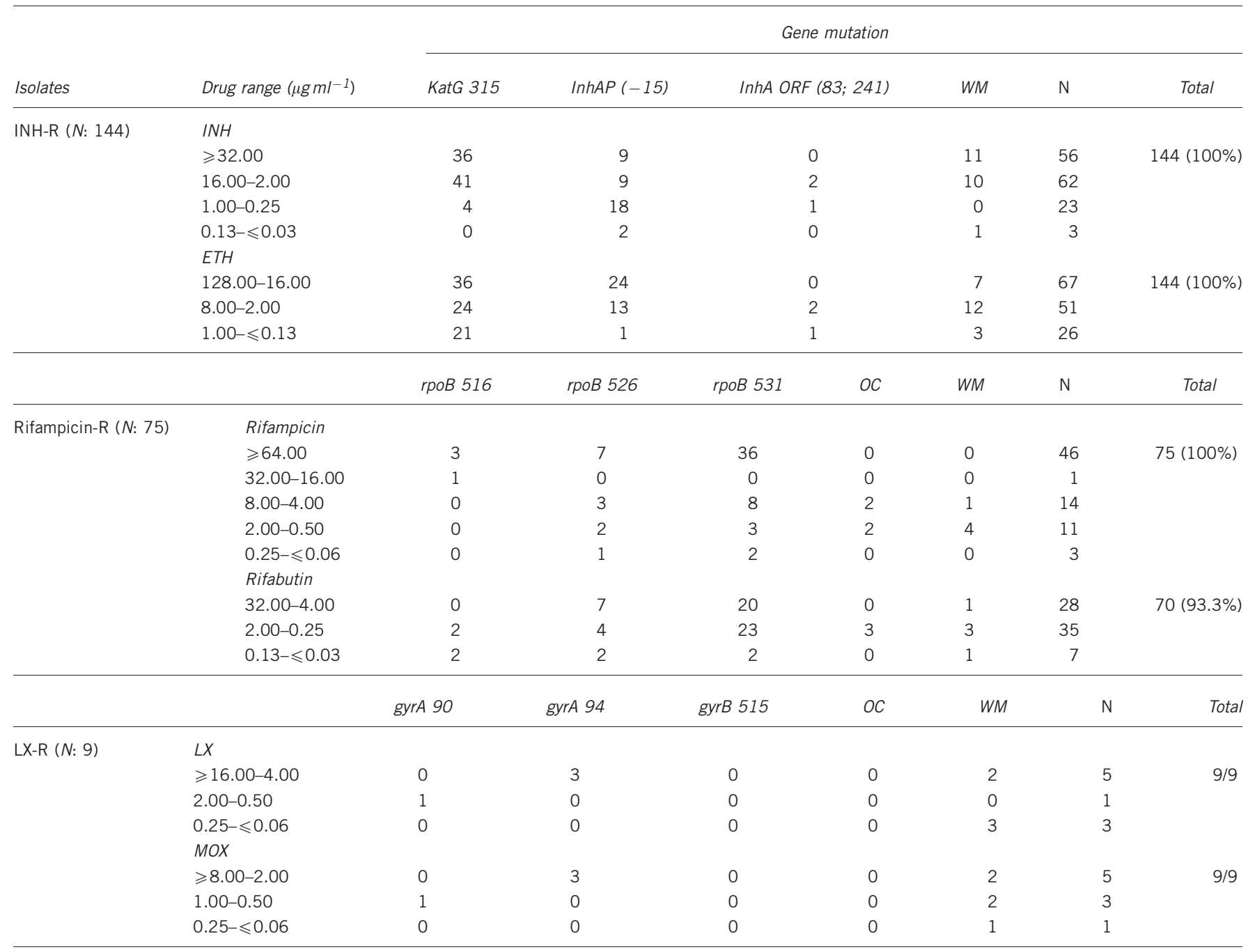

Abbreviations: ETH, ethionamide; INH-R, resistant to isoniazid; LX, resistant to levofloxacin; MOX, moxifloxacin; N, number; OC, other codons; ORF, open reading frame; rifampicin-R, resistant to rifampicin; WM, without mutation found.

ETH resistance found in these isolates. ${ }^{19,20,29}$ These findings support the importance of determining the in vitro susceptibility of the multidrug-resistant strains to ETH, as this drug is, in general, available as second-line anti-TB agent. In addition, the inhAP-15 mutation was almost fully related to the ETH resistance. Therefore, the availability of a molecular system to detect rapidly the inhAP-15 mutation would be an important tool for making a rapid decision of considering ETH for the therapeutic scheme.

Besides the mutations in inhAP, point mutations in the ethA gene that codifies for the monooxygenase EthA and that activates ETH have been reported as involved in ETH resistance in M. tuberculosis clinical isolates. Therefore, this mechanism could be responsible for the ETH resistance in the 58 isolates without inhAP-15 mutation found in this study. ${ }^{31}$

\section{Rifampicin-rifabutin}

According to previous experience, cross-resistance between rifamycins has been verified in most isolates resistant to rifampicin. ${ }^{31}$ Some authors have postulated that rpoB516 mutation confers low-level resistance to rifampicin and is not related to cross-resistance to rifabutin..$^{32}$ Owing to the low number of strains with mutation in
rpoB516 in this study, this assumption could not be confirmed. However, it is noteworthy that of the seven isolates with no crossresistance between both rifamycins, two had the rpoB516 mutation and high values of MIC to rifampicin, two had mutations in rpoB526, one with a low level of resistance and the other one with a susceptible profile of the drug (MIC_rifampicin: $1.00-0.13 \mu \mathrm{g} \mathrm{ml}^{-1}$ ). The remaining two isolates contain mutations at rpoB531 and high levels of resistance to rifampicin (MIC_rifampicin: 16.00 and $64.00 \mu \mathrm{g} \mathrm{ml}^{-1}$ ). Mutations in codons rpoB531 and rpoB526 are often related to cross-resistance between both rifamycins. ${ }^{15,32}$

\section{LX-MOX}

The three isolates with high LX-resistant level and with the gyrA94 mutation also displayed high MOX-resistant level, whereas the isolate with mutation in gyrA90 showed intermediate resistance values for both drugs. Three LX-resistant isolates according to the LJ proportion method showed MIC_LX values within the susceptibility range, and two of them displayed high MIC_MOX values. Mutations outside the quinolone-resistant determining region of the gyrA and gyrB gene or in efflux pumps may be responsible for the resistance in those isolates without any detected mutation. ${ }^{25}$ 


\section{CONCLUSION}

The main contribution of this article was to establish the general relationships between the main first-line anti-TB drugs and their second-line structural analogs in the M. tuberculosis clinical isolates spread in the southeast part of South America.

In general, isolates with high INH, rifampicin and LX resistance levels also have shown high MIC values for their analogs.

According to our results, about $17.0 \%$ of the INH-resistant isolates had MIC of around $1.00 \mu \mathrm{g} \mathrm{ml}^{-1}$; therefore, they might be inhibited by concentrations of drugs easily obtained in the serum patient after a therapeutic dose. These data suggest that a second INH concentration could be tested with the clinical aim of giving the physicians some evidence to continue INH in the treatment and consider the possibility to complete the treatment with modifications of the corresponding antibiotic doses.

As reported previously, the use of rifabutin is not recommended when there is a proved rifampicin resistance. This fact is supported by the low number of rifampicin-resistant strains that are still susceptible to rifabutin, mainly because the minimal bactericide concentration needed to kill these strains may be much higher than the serum maximum concentration (NM, personal communication). These findings discourage the addition of rifampicin analogs such as rifabutin and rifapentine as alternatives for the multidrug-resistant TB treatment in the National Tuberculosis Control Programs.

The fact that one LX-susceptible isolate was resistant to MOX might be important when considering the addition of MOX — and not only ofloxacin or LX-in second-line drug schemes, mainly in extensively drug-resistant TB cases. However, one limitation of this study is the few number of FQ-resistant strains that were tested.

This study highlights the fact that the same mutations causing resistance to the first-line anti-TB drugs can be responsible for the resistance to their respective structural analogs, might allow physicians to decide on the rapid incorporation or not of the second-line agents in the therapeutic scheme, when there is no possibility of testing them in vitro. Rare exceptions in which a strain that is resistant to a first-line drug retains susceptibility to a related second-line drug would require the ability to detect the mutation responsible for drug resistance.

\section{ACKNOWLEDGEMENTS}

We thank Marcelo Mazza and Guillermo Alonso for their technical assistance. $\mathrm{AC}$ is a fellow and BI has a fellowship from the Consejo Nacional de Investigaciones Científicas y Técnicas (CONICET) in Argentina. This work was partly financed by the FAST-XDR Project of the European Commission, FP7, CE: 201690.

1 WHO. Global Tuberculosis Control (2009) WHO/HTM/TB/2009.407.

2 WHO. Global Tuberculosis Report (2012) WHO/HTM/TB/2012.6.

3 WHO. Multidrug and Extensively Drug-Resistant TB (M/XDR-TB): 2010 Global Report on Surveillance and Response (2010) WHO/HTM/TB/2010.3.

4 Traore, H., Fissette, K., Bastian, I., Devleeschouwer, M. \& Portaels, F. Detection of rifampicin resistance in Mycobacterium tuberculosis isolates from diverse countries by a commercial line probe assay as an initial indicator of multidrug-resistance. Int. J. Tuberc. Lung Dis. 4, 481-484 (2000).

5 Hoek, K. G. et al. Fluorometric assay for testing rifampin susceptibility of Mycobacterium tuberculosis complex. J. Clin. Microbiol. 46, 1369-1373 (2008).

6 Telenti, A. et al. Detection of rifampicin-resistant mutations in Mycobacterium tuberculosis. Lancet 341, 647-650 (1993).
7 Morcillo, N. et al. A low cost, home-made, reverse-line blot hybridization assay for rapid detection of rifampicin resistance in Mycobacterium tuberculosis. Int. J. Tuberc. Lung Dis. 6, 959-965 (2002).

8 Mokrousov, I. et al. Multicenter evaluation of reverse line blot assay for detection of drug resistance in Mycobacterium tuberculosis clinical isolates. J. Microbiol. Methods 57, 323-335 (2004).

9 Caws, M. et al. Mutations prevalent among rifampin and isoniazid-resistant Mycobacterium tuberculosis isolates from a hospital in Vietnam. J. Clin. Microbiol. 44, 2333-2337 (2006).

10 Ramaswamy, S. \& Musser, J. M. Molecular genetics basis of antimicrobial agent resistance in Mycobacterium tuberculosis. 1998 Update. Tuber. Lung Dis. 79, 3-29 (1998).

11 Huitric, E., Werngren, J., Juréen, P. \& Hoffner, S. Resistance levels and $r p o B$ gene mutations among in vitro-selected rifampin-resistant $M$. tuberculosis mutants. Antimicrob. Agent Chemother. 50, 2860-2862 (2006).

12 Moghazeh, S. L. et al. Comparative antimycobacterial activities of rifampin, rifapentine, and KRM-1648 against a collection of rifampin-resistant Mycobacterium tuberculosis isolates with known rpoB mutations. Antimicrob. Agents Chemother. 40, 2655-2657 (1996).

13 Taniguchi, $\mathrm{H}$. et al. Rifampicin resistance and mutation of the rpoB gene in Mycobacterium tuberculosis. FEMS Microbiol. Lett. 144, 103-108 (1996).

14 Ohno, H., Koga, H., Kohno, S., Tashiro, T. \& Hara, K. Relationship between rifampin MICs for and rpoB mutations of Mycobacterium tuberculosis strains isolated in Japan. Antimicrob. Agents Chemother. 40, 1053-1056 (1996).

15 Almeida Da Silva, P. E. \& Palomino, J. C. Molecular basis and mechanisms of drug resistance in Mycobacterium tuberculosis: classical and new drugs. J. Antimicrob. Chemother. 66, 1417-1430 (2011).

16 Heym, B., Saint-Joanis, B. \& Cole, S. T. The molecular basis of isoniazid resistance in Mycobacterium tuberculosis. Tubercle Lung Dis. 74, 267-271 (1999).

17 Saint-Joanis, B. et al. Use of site-directed mutagenesis to probe the structure, function and isoniazid activation of the catalase/peroxidase, KatG, from Mycobacterium tuberculosis. Biochem. J. 338, 753-760 (1999).

18 Hazbón, M. et al. Population genetics study of isoniazid resistance mutations and evolution of multidrug-resistant Mycobacterium tuberculosis. Antimicrob. Agents Chemother. 50, 2640-2649 (2006).

19 Kiepiela, P., Bishop, K. S., Smith, A. N., Roux, L. \& York, D. F. Genomic mutations in the $k a t G$, inhA and $a p h C$ genes are useful for the prediction of isoniazid resistance in Mycobacterium tuberculosis isolates from Kwazulu Natal, South Africa. Tubercle Lung Dis. 80, 47-56 (2000).

20 Rozwarsky, D., Grant, G., Barton, D., Jacobs, W. R. Jr. \& Sacchettini, J. C. Modification of the NADH of the isoniazid target (InhA) from Mycobacterium tuberculosis. Science 279, 98-102 (1998).

21 Giannoni, F. et al. Evaluation of a new line probe assay for rapid identification of gyrA mutations in Mycobacterium tuberculosis. Antimicrob. Agents Chemother. 9 2928-2933 (2005)

22 Pitaksajjakul, P. et al. Mutations in the gyrA and $\operatorname{gyr} B$ genes of fluoroquinoloneresistant Mycobacterium tuberculosis from TB patients in Thailand. Southeast Asian J. Trop. Med. Public Health 36(Suppl 4), 228-237 (2005).

23 Ginsburg, A. Emergence of fluoroquinolone resistance in Mycobacterium tuberculosis during continuously dosed moxifloxacin monotherapy in a mouse model. Antimicrob. Agents Chemother. 49, 3977-3979 (2005).

24 Lee, A. S., Tang, L. L., Lim, I. H. \& Wong, S. Y. Characterization of pyrazinamide and ofloxacin resistance among drug resistant Mycobacterium tuberculosis isolates from Singapore. Int. J. Infect. Dis. 6, 48-51 (2002).

25 Almeida da Silva, P., Von Groll, A. \& Martin, A. Efflux as a mechanism for drug resistance in Mycobacterium tuberculosis. Immunol. Med. Microbiol. 63, 1-9 (2011).

26 Imperiale, B., Cataldi, A. \& Morcillo, N. Rapid detection of multidrug-resistant Mycobacterium tuberculosis by multiplex allele-specific polymerase chain reaction. Int. J. Tuberc. Lung Dis. 15, 496-501 (2011).

27 Imperiale, B. et al. First evaluation in Argentina of the GenoType ${ }^{\circledR}$ MTBDRplus assay for multidrug-resistant Mycobacterium tuberculosis detection from, clinical isolates and specimens. Rev. Argent. Microbiol. 44, 283-289 (2012).

28 Morcillo, N., Imperiale, B. \& Di Giulio, B. Evaluation of MGIT 960 and the colorimetric-based method for tuberculosis drug susceptibility testing. Int. J. Tuberc. Lung Dis. 14, 1169-1175 (2010).

29 Martin, A. et al. Multicenter study of MTT and resazurin assays for testing susceptibility to first-line anti-tuberculosis drugs. Int. J. Tuberc. Lung Dis. 9, 901-906 (2005).

30 Morcillo, N. et al. A microplate indicator-based method for determining the susceptibility of multidrug-resistant Mycobacterium tuberculosis to antimicrobial agents. Int. J. Tuberc. Lung Dis. 8, 253-259 (2004).

31 Morlock, G. P., Metchock, B., Sikes, D., Crawford, J. T. \& Cookasey, R. C. EthA, inhA, and katG loci of ethionamide-resistant clinical Mycobacterium tuberculosis isolates. Antimicrob. Agents Chemother. 47, 3799-3805 (2003).

32 Williams, D. L. et al. Contribution of $r p o B$ mutations to development of rifamycin cross-resistance in Mycobacterium tuberculosis. Antimicrob. Agents Chemother. 42, 1853-1857 (1998). 